\title{
Rooster collagen extracts from rooster by-products
}

\begin{abstract}
Collagen extracts are useful for industrial applications due to their high-water retention capacity, ability to repair rough skin, lack of color and odor problems, absence of harmful effects on human health, and low incidence of causing allergic reactions. The extraction of collagen from rooster skin could lead to an alternate source of collagen for various industries including the food industry. The collagen yields and their physical and chemical properties can be varied not only with the source but also with the treatment methods. The objective of this research was to extract collagen from rooster skin by utilizing traditional methods and pepsin digestions to compare the yields of different collagen extraction methods. $2.6 \mathrm{M}$ $\mathrm{NaCl}$ was used to precipitate collagen from pretreated skin in the presence of $0.05 \mathrm{M}$ Tris (hydroxymethyl) aminomethane ( $\mathrm{pH} 7.0)$. Statistical analyses were performed using CRD and the Student's t-test, with a $\mathrm{P}<0.05$. The average yield obtained from traditional methods was $6 \%$ in dry weight basis, while the average yield obtained for pepsin digestions was approximately $37 \%$. Molecular weights of collagen extracts from acetic acid, citric acid, alkali extractions were over $100 \mathrm{kDa}$ while those from pepsin extractions were below $66 \mathrm{kDa}$ because of the further digestion of collagen in pepsin. Acid solubilized rooster collagen had similar banding patterns as acid solubilized calf skin collagen. This indicates that the rooster collagen can be considered as an alternate source of collagen for many applications.
\end{abstract}

Volume 7 Issue 3 - 2017

\author{
Kumudini A Munasinghe,' Jurgen G Schwarz ${ }^{2}$ \\ 'Department of Biological Sciences, Salisbury University, USA \\ ${ }^{2}$ Food Science and Technology, Department of Agriculture, \\ University of Maryland Eastern Shore, USA
}

Correspondence: Kumudini A Munasinghe, Department of Biological Science, Salisbury University, Salisbury, USA, Postal Code: 2180I, Tel no + | 4105484242, Fax + | 4105436433,

Email kamunasinghe@salisbury.edu

Received: August 22, 2017 | Published: November 14, 2017

Keywords: rooster collagen, collagen extractions, collagen yields

\section{Introduction}

Collagen associated hydrolysates have desirable characteristics for various industrial applications. ${ }^{1,2}$ They have been used as important biomaterial in medical applications because of their biodegradability and weak antigenicity. ${ }^{3}$ In addition, intra-cellular and extra-cellular self-assembly of polypeptide chains and the cross-links between adjacent molecules help collagen fibrils to withstand physical stress. ${ }^{4}$ Collagen is also effective in decreasing cooking loss of deli products containing chunked chicken meat by increasing protein-protein bindings, and has the potential to improve the quality characteristics of deli rolls by improving their texture. ${ }^{5}$ Further, Mittal ${ }^{6}$ showed that collagen hydrolysates can be used as binders or extenders in meat emulsions. Moreover, collagen can also be used to make natural casings for sausages and frankfurters ${ }^{7}$ and to fill periodontal bony pockets. ${ }^{8}$ Collagen is however, deficient in the essential amino acid tryptophan and limited in some essential amino acids such as lysine, threonine and methionine. ${ }^{9}$

Collagen has been used for cosmetic and medicinal purposes since 1975 , including for the reduction of wrinkles. ${ }^{10}$ Millions of patients have been treated with collagen and approximately 280 clinical studies have been published. ${ }^{10}$ This natural substance present in the connective tissues is used for the reconstitution of the dermis and for dermal wound healing. ${ }^{11}$ It has been shown that skin replacement with a collagen-based dermal substitute gave good functional and cosmetic results. $^{12}$

Collagen fibers can be seen at the time that structure differentiation begins in early embryonic development. ${ }^{4,13}$ Diegelmann ${ }^{14}$ reported that adult skin contains about $80 \%$ type I and $20 \%$ type III collagen. In newborns, the type III content is greater than that of the adults. Collagen is one of the most abundant proteins on earth. ${ }^{15}$ The occurrence of collagen in invertebrate species was studied by Eastoe \& Pikkarainen et al., ${ }^{16,17}$ who found large amounts of collagen in octopuses, earthworms, fish, tapeworms and sea mussels.

The denaturation temperature of mammalian collagen is higher than that of collagen obtained from marine animals. Further, the mammalian collagen denaturation temperature is compatible with human body temperature, $37^{\circ} \mathrm{C}$, and is therefore extensively used for medical purposes. ${ }^{3}$ Chicken collagen can be utilized as an alternate source for biomedical purposes because denaturation temperature for chicken collagen was estimated to be $38^{\circ} \mathrm{C}$ by Sakai et al. ${ }^{18}$

Morimura et al., ${ }^{19}$ used pig skin to extract collagen using acetic acid and alkali $(\mathrm{NaOH}, \mathrm{pH} 12)$ solutions. In the same study, fat and inorganic materials were removed prior to collagen extraction and collagen yields for defatted pig skin with acetic acid and alkali extractions were $72 \%$ and $80 \%$, respectively. Another study reported that collagen yield extracted from the cuttlefish skin with acetic acid was $2 \%$ and that of pepsin digestion was $35 \%{ }^{20}$ It was also shown that efficiency in collagen extraction from the skin of bigeye snapper could be enhanced by incorporating pepsin at $20 \mathrm{kU} / \mathrm{g}$ using defatted skin during $48 \mathrm{~h}$ extraction, after an acid pre-swelling treatment for 24hours. ${ }^{21}$ This study obtained $54 \%$ collagen yield after 48 hours for bigeye snapper skin. Dry weights of chicken collagen extractions for acetic acid, citric acid, sodium hydroxide, one-step acetic acid and one-step pepsin, and two-step acetic acid and one-step pepsin for the skin extractions were $6.1,6.2,5.0,38.7$, and 40.4 percent, respectively and those of bone extractions were 4.4, 4.1, 4.1, 19.1, 20.6 percent, respectively. ${ }^{22}$ Base on the yields obtain from chicken collagen in Munasinghe et al., ${ }^{22}$ higher yields can be expected from rooster skin as an alternate source of collagen with the same five different extraction methods than from rooster bones. Further, the rooster skin collagen can be expected to have better mechanical properties than broiler chicken 
collagen, because mechanical properties of collagen varies with the fibril size, orientation, age, and anatomical location ${ }^{23}$ of the source. One-and a half year old rooster might have collagen that has better mechanical properties than the collagen extracted from 45days old broiler chicken. In addition, the yield obtained for different extraction methods can vary with the treatments utilized. The objective of this study was to extract and analyze rooster collagen, and compare yields obtained for different collagen extraction methods.

\section{Collagen extraction protocol}

\section{Rooster skin preparation}

Rooster skin was obtained from a commercial vender (Perdue chicken Salisbury, MD) and stored at $4^{\circ} \mathrm{C}$ until used. The skin was washed, and pretreated to remove non- collageneous protein, fat, and inorganic compounds with $0.1 \mathrm{~N} \mathrm{NaOH}, 10 \%$ butyl alcohol, and $0.1 \mathrm{~N}$ HCL, respectively. ${ }^{22,24}$ Two replicates were used for each extraction method, and all procedures were conducted at $4{ }^{\circ} \mathrm{C}$ with continuous stirring. The $\mathrm{NaOH}$ solution was changed every 2 hours to remove non-collagenous proteins over 6hours, and the samples were washed with distilled water. Deproteinated samples were stirred in $10 \%$ butyl alcohol with a solid/solvent ratio of 1:6 (w/v) for 48hours to remove the fat. The butyl alcohol was changed every 2 hours, and samples were washed with distilled water prior to the removal of inorganic compounds. The defatted samples were stirred in a $0.1 \mathrm{~N} \mathrm{HCl}$ solution for 24 hours with a solid/solvent ratio of $1: 6(\mathrm{w} / \mathrm{v})$ to remove inorganic compounds. The pretreated samples were washed three times in distilled water prior to conducting collagen extraction procedures.

However, it was very difficult to conduct pretreatment steps with rooster skin because of the thick fat layers attached to the skin. Therefore, fat removal time for the experiment was increased up to 48 hours with $10 \%$ butyl alcohol. The longer processing time, along with difficulties in continuous stirring, and filtering were disadvantages of utilizing rooster skin for collagen extractions.

Collagen extraction: Collagen extractions were conducted using five different extraction methods; acetic acid, citric acid, alkali, one-step acetic acid and one-step pepsin, and two-step acetic acid and one-step pepsin extractions.

Acetic acid extraction: $0.5 \mathrm{M}$ acetic acid with a solid/solvent ratio of $1: 6(\mathrm{w} / \mathrm{v})$ was used to extract collagen from rooster skin. After 48hours of collagen extraction, the sample was filtered using cheese cloth, and filtrate was used for collagen precipitation. ${ }^{24}$

Citric acid extraction: $0.5 \mathrm{M}$ citric acid solution with a solid/solvent ratio of 1:6 (w/v) was used to extract collagen from rooster skin for 48hours. The dissolved collagen in citric acid was purified by dialyzing it in distilled water at $4^{\circ} \mathrm{C}$ and the filtrate was used for the precipitation. ${ }^{18}$

$\mathrm{NaOH}$ extraction: minced rooster skin was stirred in $\mathrm{NaOH}(\mathrm{pH} 12)$ with a sample solution ratio of $1: 6(\mathrm{w} / \mathrm{v})$ at $4^{\circ} \mathrm{C}$ for 48 hours. After extraction, the sample was filtered through double layer cheese cloth, and the filtrate was used for precipitation. ${ }^{19}$

One-step acid and one-step pepsin extraction: Defatted sample was soaked in $0.5 \mathrm{M}$ acetic acid containing pepsin $(20 \mathrm{kU} / \mathrm{g}$, Sigma-Aldrich Corp., St. Louis, MO) with a sample solution ratio of 1:6 (w/v) for 48hours, and the filtrate was collected for precipitation. ${ }^{19}$
Two-step acid and one-step pepsin extraction: Collagen was extracted with 0.5 acetic acid with the solid/solvent ratio of $1: 6$ $(\mathrm{w} / \mathrm{v})$ for 24 hours. The residue was re-extracted with $0.5 \mathrm{M}$ acetic acid containing pepsin $(20 \mathrm{kU} / \mathrm{g})$ at a solid/solvent ratio of $1: 6(\mathrm{w} / \mathrm{v})$ at $4^{\circ} \mathrm{C}$ for 24 hours. The filtrates were collected and combined for precipitation. ${ }^{21}$

\section{Collagen precipitation}

2.6 $\mathrm{M} \mathrm{NaCl}$ was used to precipitate collagen in the presence of $0.05 \mathrm{M}$ Tris (hydroxymethyl) aminomethane $(\mathrm{pH} 7.0)$. The precipitates were collected by centrifuging at $20,000 \mathrm{xg}$ for $60 \mathrm{~min}$ at $4^{\circ} \mathrm{C}$. The pellets were dissolved in $0.5 \mathrm{M}$ acetic acid and samples were dialyzed against ten volumes of $0.1 \mathrm{M}$ acetic acid and distilled water.

\section{SDS-polyacrylamide gel electrophoresis (SDS-PAGE)}

The method developed by Nalinanon et al., ${ }^{21}$ was used to perform SDS-PAGE with modifications. Each collagen extract $(0.2 \mathrm{mg})$ was dissolved in a $0.02 \mathrm{M}$ sodium phosphate buffer $(100)$ containing $1 \%$ SDS with $3.5 \mathrm{M}$ urea $(\mathrm{pH} 7.2)$ and centrifuged at $8,500 \mathrm{x}$ g for $5 \mathrm{~min}$ at room temperature. Solubilized collagen samples were mixed with the sample buffer containing $0.05 \mathrm{M}$ Tris- $\mathrm{HCl}, 4 \%$ SDS and $20 \%$ glycerol at a sample/solution ratio of 1:1 and the samples were boiled in water for $12 \mathrm{~min}$. After cooling down, samples were loaded into a gradient SDS-PAGE gel (4\%-20\%) and subjected to electrophoresis using a mini protein 11 unit (Bio-Rad Laboratories Inc., Richmond, $\mathrm{CA})$ at $125 \mathrm{~V}, 3 \mathrm{~A}, 300 \mathrm{~W}$ for 2 hours. The gel was then stained with sypro ruby stains. The molecular weights of collagen extracts were estimated with a molecular-weight marker (Sigma- Aldrich Corp., St. Louis, MO) and were also compared with acid hydrolyzed type I calf skin collagen.

\section{Statistical analysis}

The data was analyzed using a Complete Randomized Design (CRD) and the Student's t-test. CRD was performed for the collagen yield comparison study and two replicates were used for the analysis. The Student's t-test was used to compare the yields in pepsin treatments. The differences were considered significant when $\mathrm{P}$ value was less than 0.05 .

\section{Results and discussions}

\section{Yield comparison}

Five different extraction procedures were conducted to extract rooster collagen to compare yield differences for each treatment method. The collagen yield was calculated as a percentage of the dry weight of the initial weight of the skin. Average collagen yields (Table 1) for two replicates of acetic acid, citric acid, $\mathrm{NaOH}$, onestep acetic acid one-step pepsin, and two-step acetic acid one-step pepsin extractions for the rooster skin were $6.5,5.7,6.8,36.2$, and 37.5 percent dry weight, respectively. The mean collagen yields for pepsin extraction methods were statistically different than traditional extraction methods at the significance level at $\mathrm{P}<0.05$. The methods employed for pepsin extraction after pre-swelling rooster skin with acetic acid gave higher yields than traditional methods with acetic acid, citric acid, and $\mathrm{NaOH}$. However, there were no significant difference in yields obtained from one-step acetic acid and one-step pepsin and two-step acetic acid and one-pepsin extraction methods. In addition, as an advantage, the rooster skin collagen extractions were light in color and had no objectionable odor. 
Table I Yield comparison of rooster collagen extracts for different extraction methods

\begin{tabular}{|c|c|c|c|}
\hline Extraction methods & Replicate I (\% Yield) & Replicate 2 (\% Yield) & Average* $*$ SD (\% Yield) \\
\hline Acetic acid & 6.6 & 6.3 & $6.45^{\mathrm{a}} \pm 0.2$ \\
\hline Citric acid & 5.9 & 5.5 & $5.7^{\mathrm{a}} \pm 0.3$ \\
\hline $\mathrm{NaoH}$ & 7.1 & 6.5 & $6.8^{\mathrm{a}} \pm 0.4$ \\
\hline One-Step Acid One-Step Pepsin & 36.26 & 36.1 & $36.18^{\mathrm{b}} \pm 0.1$ \\
\hline Two-Step Acid One-Step Pepsin & 37.8 & 37.1 & $37.45^{b} \pm 0.5$ \\
\hline
\end{tabular}

The rooster skin was completely digested in pepsin extraction procedures in the presence of acetic acid and gave much higher yields than the traditional methods which did not give complete digestion of the skin. These results suggested that pepsin with acetic acid can break more bonds between collagen than the other traditional methods. This observation for pepsin digestion was in agreement with Nagai \& Nalinanon et al., ${ }^{20,21}$ who obtained higher collagen yields with pepsin extractions than traditional extraction methods. However, these results were in disagreement with Morimura et al., ${ }^{19}$ who had higher collagen yields for acetic acid $(72 \%)$ and alkali $(80 \%)$ extractions for collagen that was extracted from defatted pig skin. Further, the two-step acetic acid one-step pepsin did not have a significant increase in yield even though it took 24 hours more processing time than one-step acetic acid one-step pepsin extraction method. This result was in agreement with Munasinghe et al.,22 who suggested that the collagen extraction with one-step acetic acid and one-step pepsin could be the most appropriate method in terms of the time and the expenses involved with collagen extraction for industrial uses.

However, rooster collagen yields obtained from each extraction methods were less than those of broiler skin collagen yields, 6.1, 6.2, $5.0,38.7$, and $40.4 \%$ respectively, as was shown in Munasinghe et al. ${ }^{22}$ The difficulties in recovery of rooster skin samples during the pretreatments and filtration steps were lead to give a lower collagen yields for rooster skin than that from broiler chicken skin.

\section{Sodium dodecyl sulfate-polyacrylamide electrophoresis (SDS-PAGE)}

The collagen extracts from all five extraction methods were analyzed using the SDA-PAGE. The first lane of the image (Figure 1) had the molecular weight marker and the second lane had calf skin collagen. Lanes 3, 4, 5, 6, 7 and 8 were acetic acid, citric acid, $\mathrm{NaOH}$, acetic acid, two-step acetic acid and one-step pepsin, and one-step acetic acid and one-step pepsin extractions, respectively. The old extraction methods, acetic acid, citric acid, and $\mathrm{NaOH}$ extractions, had bands that were more than $100 \mathrm{kD}$ molecular weights and lower molecular weights were observed in pepsin-solubilized collagen (less than $66 \mathrm{kD}$ ). There were no differences in relative mobility of acidsolubilized rooster collagen and calf skin type 1 collagen.

These results were in agreement with the findings by Nalinanon et al., ${ }^{21}$ who showed that there were no differences in the relative mobility of high molecular weights between acid extracted collagen from bigeye snapper skin and calf skin type I collagen. The higher molecular weights in old extraction procedures suggest that cross-links did not fully digest by acetic acid, citric acid, and $\mathrm{NaOH}$ extraction procedures. The lower molecular weights (less than $66 \mathrm{kD}$ ) for pepsin extracted collagen in Lane 7 and 8 suggest that pepsin digests more peptide bonds than that with acid and alkali treatments. These results in agreement with Nalinaanon et al., ${ }^{21}$ who found lower molecular weights in pepsin extracted collagen compared to acid extracted collagen and speculated that the high molecular-weight components might be degraded to smaller components by the pepsin action. Miller et al., ${ }^{9}$ also suggested that intra-molecular cross-links were broken with pepsin digestion resulting in lower molecular weights.

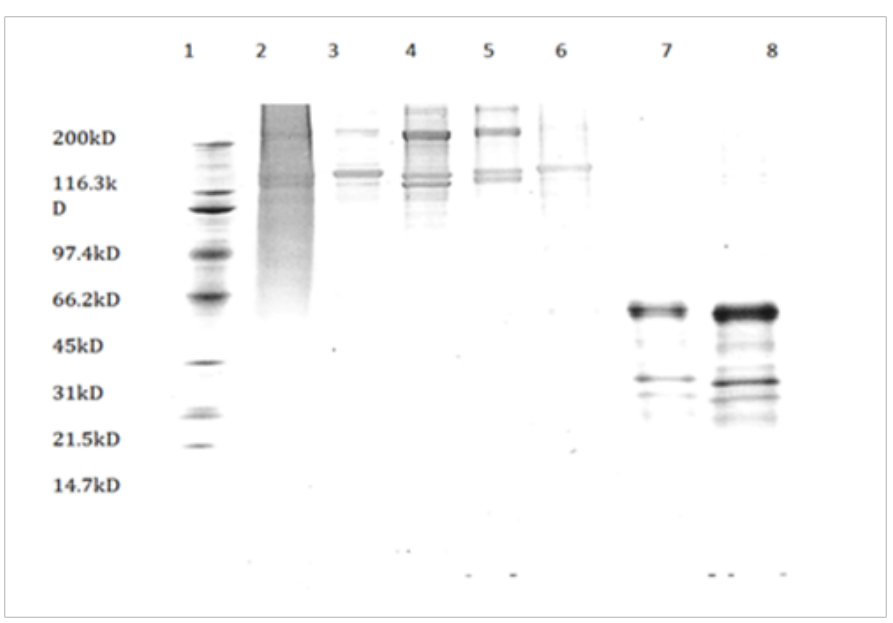

Figure I SDS-PAGE protein patterns with sypro ruby stain (I) Molecular weight marker, (2) Calf skin collagen, (3) Acetic acid-solubilized collagen, (4) Citric acid solubilized collagen, (5) Akaline-solubilized collagen, (6) Acetic acidsolubilizes collagen (7) Two-step acid one step pepsin solubilized collagen (8) One step acid one step pepsin solubilized collagen.

The electrophoretic patterns of collagen extracts were analyzed in a non-reducing environment in the absence of $\beta$-mercaptoethanol as it has been shown that there were no differences in the electrophoretic patterns with or without $\beta$-mercaptoethanol in acid solubilized collagen and pepsin solubilized collagen with skin of Brownstripe red snapper \& Nalinanon et al., ${ }^{21,25}$ also found that collagen does not contain any disulfide bonds.

Several studies indicated that age and available feed could influence the collagen structure. For example, Foegeding \& Sikorski et al., ${ }^{1,26}$ showed that starving fish had more cross-linked collagen than that of well-fed fish. Foegeding et al., ${ }^{26}$ showed that the high molecular weight cross-linked molecules in collagen increased with animal age. The rate of cross-link formation in collagen may be different between species. For example, the cross-linking rate of fish collagen may be different than that in rooster collagen. Sikorski et al., ${ }^{1}$ showed that the bands were thick and mechanically stronger in starving fish than that in the fish that were adequately nourished. Roosters may have more cross-linked molecules in collagen because of their longer life spans than those of broilers, which have shorter life and are well-fed with nutrients. Therefore, rooster collagen may be mechanically stronger than the collagen obtained from well-fed broilers. ${ }^{27}$ 


\section{Conclusion}

Collagen was extracted from rooster skin using five different extraction procedures: acetic acid, citric acid, $\mathrm{NaOH}$, one-step acetic acid and one-step pepsin and two-step acetic acid and onestep pepsin extractions. minced rooster skin was pretreated to remove non-collagenous protein, mineral, and fat. The removal of non-collagenous protein and mineral from rooster skin took 6 and 24hours, respectively, and the removal of thick fat layers in rooster skin took 48hours. Average collagen yields for collagen extracts with acetic acid, citric acid, $\mathrm{NaOH}$, one-step acid one-step pepsin and two-step acid one-step pepsin were $6.45,5.7,6.8,36.18,37.45 \%$ dry weight, respectively. Higher yields could be obtained from the pepsin digestion and the efficiency in collagen extraction could be enhanced by incorporating pepsin at $20 \mathrm{k}$ units $/ \mathrm{g}$ with acetic acid. These results indicated that the pepsin could digest more inter and intra molecular cross-links than traditional methods. However, pepsin-solubilized collagens showed lower molecular weights than those of the older extraction methods. Acetic acid, citric acid, and alkali extracted collagen had molecular weight over $100 \mathrm{kDa}$ and pepsin digestions had less than $66 \mathrm{kDa}$. Further, rooster collagen extracts were light in color and had no objectionable odor to disguise.

This research suggests that the rooster collagen can be utilized as an alternate source of collagen for many industries including the food industry. Rooster collagen may be mechanically stronger than other collagen sources such as broilers that have shorter life spans than roosters.

\section{Acknowledgements}

This work was supported by Evans-Allen project. The authors would like to thank Dr. Kuwamy Nyame and Mr. Matthew Whittiker at University of Maryland Eastern Shore for their technical assistance. The authors specially thank Banuja Munasinghe for assisting them with lab work. The authors also are grateful to Drs. Christopher Briand and Alexander Halperin at Salisbury University for reviewing this article.

\section{Conflict of interest}

The author declares no conflict of interest.

\section{References}

1. Sikorski ZE, Sikorski A, Kolakowska A, et al. The nutritive composition of the major groups of marine food organisms. Seafood resources, nutritional composition and preservation. 1990. p. 29-54.

2. Wess TJ, Orgel JP. Changes in collagen structure: Drying dehydrothermal treatment and relation to long term deterioration. Thermochemica Acta. 2000;365(1-2):119-128.

3. Zhang Z, Li G, Shi B. Physicochemical properties of collagen, gelatin and collagen hydrolysate derived from bovine limed split wastes. Journal of the Society of Leather Technologists and Chemists. 2005;90:23-27.

4. Marcel EN. Collagen. USA: CRC Press, Inc; 1988. 1:312.

5. Schilling MW, Daigle SP, Alvarado CZ, et al. Effects of collagen addition on the functionality of PSE-like and normal broiler breast meat in a chunked and formed deli roll. J Muscle Foods. 2005;16(1):46-53.

6. Mittal GS. Meat in emulsion type sausages-An overview. J Food Agric and Environ. 2005;3(2):101-108.
7. Munasinghe KA, Schwarz JG, Whittiker M. Utilization of chicken by-products to form collagen film. Journal of Food Processing. 2015;2015:6

8. Fabinger A, Krekeler G, Vogel D. Uses of collagen in the treatment of periodontal bony pockets. Dtsch Zahnarztl Z. 1980;35(1):139-141.

9. Miller EJ, Gay S. The collagen: an overview and update. Methods Enzymol. 1987;144:3-41.

10. Fflageul G, Aharoni C. Collagen injectable. Annales de chirurgie plastique esthetique. 2004;49:460-464.

11. Ruszczak Z. Effect of collagen matrices on dermal wound healing. Adv Drug Delivery Rev. 2003;55(12):1595-1611.

12. Wissser D, Steffers J. Skin replacement with a collagen based derma substitute, autologous keratinocytes and fibroblasts in burn trauma. Burns. 2003;29(4):375-380.

13. Imhof M, Trueb B. Alternative splicing of the first F3 domain from chicken collagen XIV affects cell adhesion and heparin binding. $J$ Boil Chem. 2001;276(12):9141-9148.

14. Diegelmann RF. Collagen Metabolism. Wounds. 2001;13(5):177182.

15. Van Der Rest M, Garrone R. Collagen family of proteins. FASEB J. 1991;5(13):2814-2823.

16. Eastoe JE. In treatise on collagen. USA: Academic Press; 1967.

17. Pikkarainen J, Rantanen J, Vastamaki M, et al. Eur J Biochem. 1968;4:555.

18. Sakai R, Ikeda S, Isemura T. Soluble collagen of chicken leg tendon; Its denaturation temperature and hydrodynamic properties. Bull Chem Soc Jpn. 1967;40:2890-2894.

19. Morimura S, Nagata H, Uemure Y, et al. Development of an effective process for utilization of collagen from livestock and fish waste. Process Biochemistry. 2002;37(12):1403-1412.

20. Nagai T, Yamashita E, Taniguchi K, et al. Isolation and characterization of collagen from the outer skin waste material of cuttlefish (Sepia lycidas). Food Chemistry. 2001;72:425-429.

21. Nalinanon S, Benjakul S, Visessanguan W, et al. Use of pepsin for collagen extraction from the skin of bigeye snapper (Priacanthus tayennus). Food Chemistry. 2007;104(2):593-601.

22. Munasinghe KA, Schwarz JG, Nyame AK. Chicken collagen from low market value by-products as an alternate source. Journal of Food Processing. 2014;2014:6.

23. Parry DAD. The molecular and fibrillar structure of collagen and its relationship to mechanical properties of connective tissue. Biophys Chem. 1988;29(1-2):195-209.

24. Kittiphattanabawon P, Benjakul S, Visessanguan W, et al. Characterization of acid-soluble collagen from skin and bone of bigeye snapper (Priacanthus tayenus). Food Chemistry. 2005;89:363-372.

25. Jongjareonrak A, Benjakul S, Viseeanguan W, et al. Isolation and characterization of collagen from bigeye snapper (Priacanthus marcracanthus) skin. J Sci Food and Agric. 2005;85(7):1203-1210.

26. Foegeding EA, Laneir TC, Hultin HO. Characteristics of edible muscle tissues. In: Owen Fennema R, editor. Food Chemistry. 1996;15(3):902-906.

27. Satterlee LD, Zachariah NY, Levin E. Utilization of beef and pork skin hydrolyzates as binder/extenders in sausage emulsions. $J$ food Sci. 1973;38(2):268-270. 